\title{
Evaluation of the Effect of Water on Three Different Light Cured Composite Restorative Materials Stored in Water: An In Vitro Study
}

\author{
Basawaraj Biradar, ${ }^{1}$ Sudharani Biradar, ${ }^{2}$ and Arvind $\mathrm{MS}^{3}$ \\ ${ }^{1}$ Department of Conservative Dentistry \& Endodontics, Rural Dental College, Pravara Medical Trust Campus, \\ Loni, Rahata Taluka, Ahmednagar District, India \\ ${ }^{2}$ Department of Oral Medicine, Diagnosis and Radiology, Rural Dental College, PMT Loni, Rahata Taluka, \\ Ahemadnagar Dist 413736, India \\ ${ }^{3}$ Department of Conservative Dentistry and Endodontics, Sri Rajiv Gandhi College of Dental Sciences, Banglore 560032, India
}

Correspondence should be addressed to Basawaraj Biradar, dr.basawaraj@rediffmail.com

Received 8 June 2011; Accepted 11 October 2011

Academic Editor: J. D. Eick

Copyright () 2012 Basawaraj Biradar et al. This is an open access article distributed under the Creative Commons Attribution License, which permits unrestricted use, distribution, and reproduction in any medium, provided the original work is properly cited.

Objectives. The objective of this in vitro study was to investigate whether weight gain or loss in the three different composites occurs due to water absorption when they are stored in water. Methods. The composite restorative materials selected for this study included a microfine hybrid (Synergy) and two nanofilled composite restorative materials (Ceram X and Filtek Supreme Ultra). Twenty specimens of each material were fabricated of each composite material. Group A: Filtek Supreme Ultra, Group B: Synergy, Group C: Ceram X. Then all the specimens were stored in $10 \mathrm{ml}$ Distilled water containing test tubes and placed in incubator at $37^{\circ} \mathrm{C}$ for six weeks. The weight changes of these specimens were measured daily for the first week and later once a week for next five weeks by using an electrical analytical balance. Results. The data was analyzed by one-way analysis of variance and Student's $t$ test. All groups showed maximum amount of water absorption in the first week than gradual decrease in the water absorption from the second to the sixth week, as compared to the first week and there is no statistically significant difference between the groups tested. Conclusion. All the composite restorative material absorbs some amount of water. The water absorption of the composite may decrease the physical and mechanical properties of the composites; hence it is necessary to consider the type of the material before starting the treatment.

\section{Introduction}

The attractiveness of tooth-colored restorations has stimulated research in this particular area of operative dentistry during recent years; patients are increasingly demanding esthetic restorations not only in the anterior teeth but also in the posterior teeth. Dental material composites are today used widely, not only because of their esthetic properties but also for the ability to adhere to tooth substance $[1,2]$.

Mechanical properties of composites are not only influenced by their chemical composition but also by the environment to which they are exposed. The corrosion process promoted by water and the presence of constant load on the surface of resin are responsible for the appearance and propagation of interfacial debonding, matrix cracking, superficial flaws, filler dissolution, and filler particle dislodge ment [3].

Nanotechnology is also known as molecular nanotechnology, or molecular engineering is the production of functional material and the structures in the range of 0.1 to 100 nanometers by various physical and chemical methods. The intense interest in nanomaterial, to provide dramatic improvement in electrical, chemical, mechanical, and optical properties [4].

The problem associated with these restorative materials is water absorption as they are continuously bathed in saliva; for resin-based composite materials water absorption may induce weakening of the matrix and breakdown of resin filler 
TABLE 1: Materials used.

\begin{tabular}{lccl}
\hline Materials used & Manufacturer & Composite type & Matrix \\
\hline $\begin{array}{l}\text { Filtek Supreme Ultra } \\
\text { (Group A) }\end{array}$ & 3M ESPE & Nanocomposite & $\begin{array}{l}\text { Nanocomposite, Universal restorative material. Aggregated } \\
\text { zirconia/silica cluster filler, with an average particle size of } \\
0.6-1.4 \text { micron }\end{array}$ \\
Synergy (Group B) & Coltene Whaledent & Nanohybrid & $\begin{array}{l}\text { Microfine hybrid BisGMA, BisEMA, TEGDMA, strontium } \\
\text { glass, barium glass, Amorphous silica }\end{array}$ \\
Ceram X (Group C) & Dentsply & Nanocomposite & $\begin{array}{l}\text { Nanoceramic methacrylate-modified polysiloxane, } \\
\text { dimethacrylate resin, fluorescence pigment, camphorquinone. }\end{array}$ \\
\hline
\end{tabular}

interface. It is also expected that absorption of water will be accompanied by hygroscopic expansion of composite which may be able to compensate for the effect of polymerization shrinkage and relieve stresses [1].

The dimensional changes in composite restorative materials placed in the cavity are the result of shrinkage of resin monomer during polymerization. Shrinkage is compensated by the expansion resulting from the water absorption of set resin. This fact has drawn much attention regarding the adaptation of composite to the dental cavity walls $[2,5,6]$.

Water sorption actually increases with cross-linker concentration, suggesting that the chemical nature of crosslinking agent may supercede the effect of higher molecular density; high level of porosity or microvoids has also been shown to facilitate fluid transport into and out of the polymer.

So the aim of this study is to evaluate the effect of water on three different light-cured composite restorative materials stored in water.

\section{Materials and Methods}

Twenty specimens from each composite material (Table 1) were prepared using brass mold $(6 \mathrm{~mm}$ diameter $\times 2 \mathrm{~mm}$ height). The composite material was covered with acetate strips and compressed between 2 glass slabs to remove voids and extrude excess composite material. The composite was then light cured through the acetate strip for 40 seconds on both the sides by using QTH light-curing unit (QHL75, Dentsply). The light-curing unit was held as close to the specimen as possible and cured at an intensity of $450 \mathrm{~mW} / \mathrm{cm}^{2}$. The tip diameter of the light-curing unit was $11 \mathrm{~mm}$ in diameter [1].

Following light curing, the specimens were removed from the mold and finished with carborundum paper and later polished with coarse, medium, and fine Sof-Lex discs (3M ESPE) in respective orders. The specimens were then weighed by electrical analytical balance (DANVER INSTRUMENT), and each specimen was placed in separate test tube (BOROSIL) containing $10 \mathrm{~mL}$ distilled water. The specimens were sealed in a test tube with cotton pellet and placed in an incubator for 6 weeks at $37^{\circ} \mathrm{C}$ (Figure 1).

Weight change of the specimen was measured according to the ISO 4049 (International Organization of Standardization) original plan (1985), and water solubility of the specimen was determined as per ADA specification no. 8 (1978) [7].

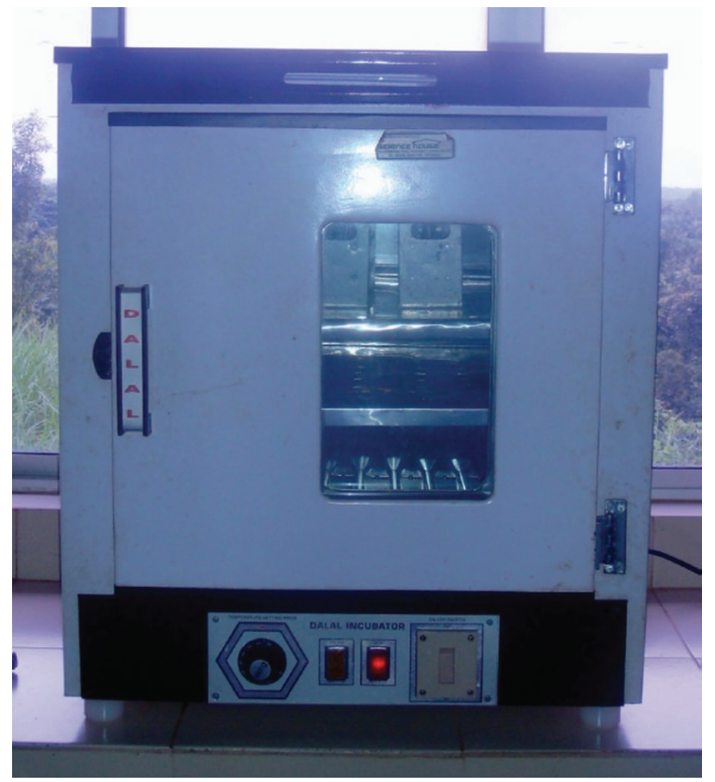

Figure 1: Specimens incubated for $37^{\circ} \mathrm{C}$ for six weeks.

After 24 hours, the specimens were removed and placed on the filter paper (Whatman) for a period of $1 \mathrm{~min}$ to drain excess water and then weighed accurately using an electrical analytical balance (Figure 2).

After weighing the specimens, they were transferred to test tubes filled with $10 \mathrm{~mL}$ of fresh distilled water.

The procedure was repeated every day for the first week and then once a week for the next five weeks.

Data obtained was analyzed statistically using analysis of variance (ANOVA) and Student's $t$ test.

The data was analyzed using multivariate approach of repeated measures analysis of variance (ANOVA) of SPSS Version 13.00 .

\section{Results}

The data was analyzed by One-way analysis of variance and Student's $t$ test.

All groups showed maximum amount of water absorption in the first week than gradual decrease in the water absorption from the second to the sixth week (Tables 2 and 3).

There was no significant difference noted among the materials $(P>0.05)$. As a result, the difference between the groups was not compared. 
TABLE 2: The mean weights of three composite specimen measured daily during the first week of the observation.

\begin{tabular}{lcccc}
\hline & No. of observations & Group A & Group B & Group C \\
\hline Initial & 20 & $929.2(28.140)$ & $910.7(18.979)$ & $905.6(15.806)$ \\
First day & 20 & $932.5(26.963)$ & $916.7(19.074)$ & $908.3(15.267)$ \\
Second day & 20 & $933.8(27.976)$ & $919.1(16.368)$ & $910.0(15.499)$ \\
Third day & 20 & $936.2(26.246)$ & $921.2(15.161)$ & $911.7(15.291)$ \\
Fourth day & 20 & $938.0(23.576)$ & $922.8(15.087)$ & $913.5(14.855)$ \\
Fifth day & 20 & $940.4(25.124)$ & $924.4(15.916)$ & $915.5(15.157)$ \\
Sixth day & 20 & $943.8(25.614)$ & $928.0(14.706)$ & $917.5(14.652)$ \\
\hline
\end{tabular}

(standard deviations are given within brackets).

TABLE 3: The mean weights of three composite specimen measured daily during the entire period of the observation.

\begin{tabular}{lcccc}
\hline & No. of observations & Group A & Group B & Group C \\
\hline Initial & 20 & $929.2(28.140)$ & $910.7(18.979)$ & $905.6(15.806)$ \\
First week & 20 & $943.8(25.614)$ & $928.0(14.706)$ & $917.5(14.652)$ \\
Second week & 20 & $945.4(25.488)$ & $929.5(14.580)$ & $919.4(13.808)$ \\
Third week & 20 & $947.7(26.725)$ & $930.6(14.303)$ & $920.3(13.632)$ \\
Fourth week & 20 & $950.2(26.998)$ & $931.2(14.722)$ & $922.1(12.377)$ \\
Fifth week & 20 & $953.3(28.507)$ & $932.8(14.388)$ & $923.4(12.445)$ \\
Sixth week & 20 & $955.3(30.479)$ & $934.4(13.936)$ & $924.5(12.441)$ \\
\hline
\end{tabular}

(standard deviations are given within brackets).

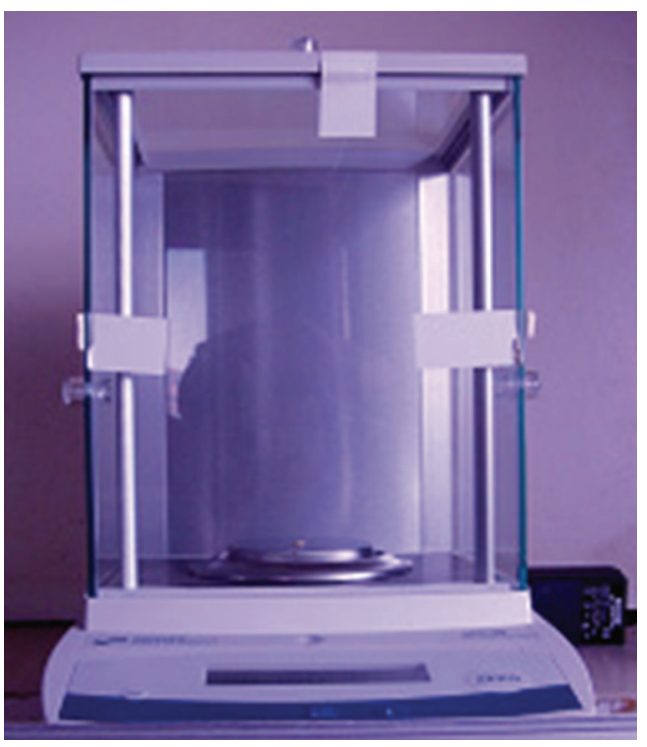

FIGURE 2: Specimen placed in electrical analytical balance.

Figure 3 shows the weight change of all the specimens of one week water storage measured daily, while Figure 4 shows the weight changes of all specimens during the test period measured weekly.

\section{Discussion}

Weight change in water was evaluated because saliva is a dilute fluid consisting of $99.5 \%$ of water. The concentrations of dissolved solids (organic or inorganic) are characterized

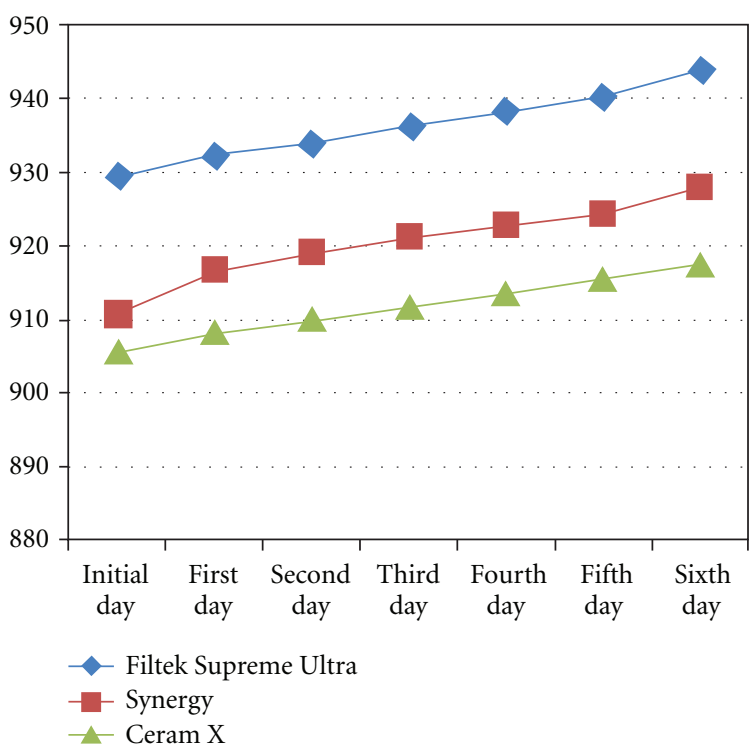

FIGURE 3: Line graph showing changes in the weight ofall study groups measured daily ( $x$-axis measures the days and $y$-axis measures the weight in grams).

by wide variations, both between individual and within a single individual. Due to this variation, water was used as test standard [1].

Brass was chosen for this study, because many of its physical properties are similar to those of the tooth substance. For example, Young's modulus of brass is very close to that of enamel while its hardness lies in between the hardness of enamel and dentin. The coefficient of thermal expansion of brass is similar to that the tooth structure $[2,8]$. 
TABLE 4: The mean weight changes in the three groups during the first week of observation (initially day to the sixth day).

\begin{tabular}{|c|c|c|c|c|c|c|}
\hline \multicolumn{7}{|c|}{ Paired difference } \\
\hline \multirow[t]{2}{*}{ Groups } & \multirow[t]{2}{*}{ Mean difference } & \multirow[t]{2}{*}{ Std. error } & \multicolumn{2}{|c|}{$95 \%$ confidence interval for the mean difference } & \multirow[t]{2}{*}{$t$} & \multirow[t]{2}{*}{$p$} \\
\hline & & & Lower limit & Upper limit & & \\
\hline Group A & 14.600 & 2.614 & 9.129 & 20.071 & 5.585 & $<0.001$ \\
\hline Group B & 17.350 & 2.141 & 12.868 & 21.832 & 8.102 & $<0.001$ \\
\hline Group C & 11.900 & 1.499 & 14.184 & 23.576 & 7.939 & $<0.001$ \\
\hline
\end{tabular}

TABLE 5: The mean weight changes in the three groups during the entire period of the observation (Initial day to the sixth week).

\begin{tabular}{|c|c|c|c|c|c|c|}
\hline \multicolumn{7}{|c|}{ Paired difference } \\
\hline \multirow[t]{2}{*}{ Groups } & \multirow[t]{2}{*}{ Mean difference } & \multirow[t]{2}{*}{ Std. error } & \multicolumn{2}{|c|}{ 95\% confidence interval for the mean difference } & \multirow[t]{2}{*}{$t$} & \multirow[t]{2}{*}{$p$} \\
\hline & & & Lower limit & Upper limit & & \\
\hline Group A & 26.150 & 3.565 & 18.688 & 33.612 & 5.585 & $<0.001$ \\
\hline Group B & 23.700 & 2.090 & 19.325 & 28.075 & 8.102 & $<0.001$ \\
\hline Group C & 18.850 & 2.229 & 14.184 & 23.516 & 7.939 & $<0.001$ \\
\hline
\end{tabular}

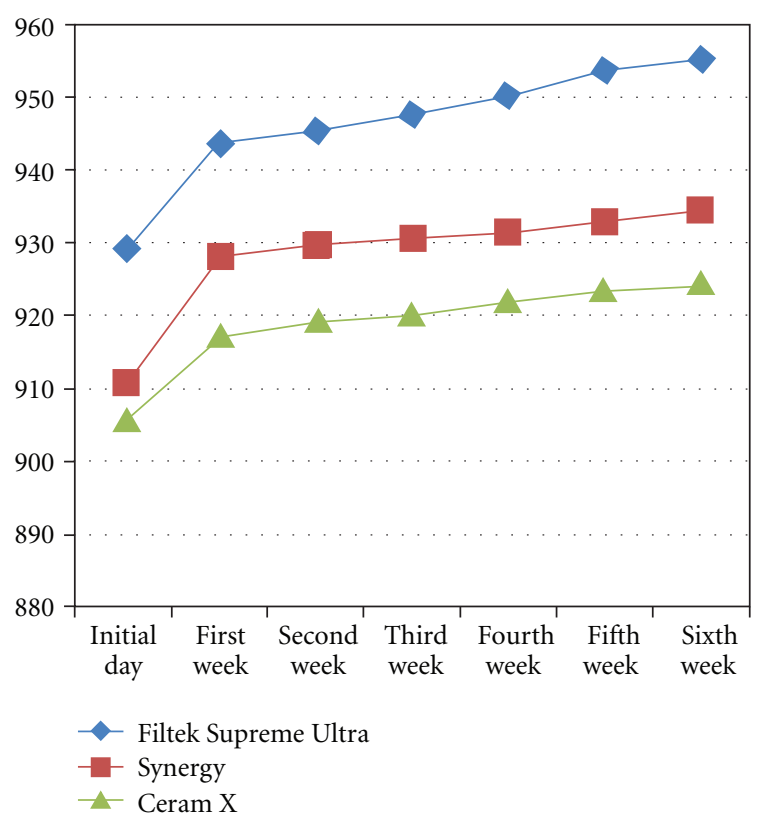

FIGURE 4: Line graph showing changes in the weight all study groups measured weekly ( $x$-axis measures the weeks and $y$-axis measures the weight in grams).

Quartz-tungsten-halogen light-curing unit was used having an intensity of $450 \mathrm{~mW} / \mathrm{cm}^{2}$ and wavelength between 400 and $500 \mathrm{~nm}$ which was sufficient to cure composite specimens up to a depth of $2 \mathrm{~mm}[9,10]$.

Acetate strips were used to prevent the formation of oxygen-inhibited layer on the surface of the composite [11].

The factors which affect the amount of water absorption of the composite restoration materials are the resin content, filler content, curing time, distance from composite cured and the coupling agent [12-16]. The more the filler content of the composite the lesser will be the water absorption $[12,17]$. The proper the bonding of the coupling agent the lesser the water absorption $[1,18]$.
This study showed maximum amount of water absorption in the first week of the experiment [1, 19-21]. The dimensional changes in composite restorative materials in the first week were the result of shrinkage of resin monomer during polymerization in the first week [22]. Shrinkage is compensated by the expansion resulting from the water absorption of set resin. This fact has drawn much attention regarding the adaptation of composite to the dental cavity walls $[2,4,5]$.

The study done by Knobloch et al. also showed maximum amount of water absorption in the first week of the experiment [20]. The study done by keyf and Yalçin also showed maximum amount of water absorption in the first week of the experiment [1]. The study done by Hegde and Biradar also showed maximum amount of water absorption in the first week of the experiment [19].

There is no statistically significant difference between the groups tested, but this study showed Synergy absorbs maximum amount of water compared to Filtek Supreme Ultra and Ceram X in the first week of the study (Table 4). This is because Synergy contains increased resin to filler ratio, it showed maximum amount of water absorption $[1,23]$. However, in this study only the relationship among immersion time, the water absorption of the resin, and the thickness of the specimen is focused. Weight loss due to dissolution was not included in the measurement; the diffusion coefficient and thickness of the specimen were affected by the amount of water absorption [2].

In this study all material showed $>90 \%$ of final volumetric expansion and change in weight within 7 days thereafter followed slower and more gradual increase in volume and weight [7]. In this study Filtek Supreme Ultra showed maximum amount of water absorption from the second to the sixth week compared to Ceram X and Synergy (Table 5). This two-stage expansion may be caused due to hydrolytic degradation of monomer bonds or stretching of these bonds beyond their elastic limit causing them to rupture [24].

The study done by Iwami et al. also showed more than $90 \%$ of the water absorption occurred in the first week [25]. 
The increase in the dimension shown by the materials may be beneficial in relieving some of internal polymerization shrinkage stresses and increase the longevity of the adhesive union to surrounding tooth [20].

Studies on the amount of weight loss due to dissolution, diffusion coefficient, thickness of the specimen, and changes in physical and mechanical properties are further required before conclusive clinical assessment.

\section{Conclusion}

The present in vitro study evaluated the effect of water on microfine hybrid (Synergy) and two different nanofilled (Filtek Supreme Ultra and Ceram X) composite restorative materials.

The following conclusions were drawn.

(1) All the groups showed some amount weight gain due to water absorption.

(2) All groups showed maximum amount of weight gain in the first week and slowly decrease in the amount of water absorption from second to sixth week.

(3) There is no statistically significant difference between the groups tested.

\section{References}

[1] F. Keyf and F. Yalçin, "The weight change of various lightcured restorative materials stored in water," Journal of Contemporary Dental Practice, vol. 6, no. 2, pp. 72-79, 2005.

[2] Y. Momoi and J. F. McCabe, "Hygroscopic expansion of resin based composites during 6 months of water storage," The British Dental Journal, vol. 176, no. 3, pp. 91-96, 1994.

[3] M. Braden, E. E. Causton, and R. L. Clarke, "Diffusion of water in composite filling materials," Journal of Dental Research, vol. 55, no. 5, pp. 730-732, 1976.

[4] R. L. Bowen, J. E. Rapson, and G. Dickson, "Hardening shrinkage and hygroscopic expansion of composite resins," Journal of Dental Research, vol. 61, no. 5, pp. 654-658, 1982.

[5] C. Huang, F. R. Tay, G. S. P. Cheung, L. H. Kei, S. H. Y. Wei, and D. H. Pashley, "Hygroscopic expansion of a compomer and a composite on artificial gap reduction," Journal of Dentistry, vol. 30, no. 1, pp. 11-19, 2002.

[6] T. Hirasawa, S. Hirano, S. Hirabayashi, I. Harashima, and M. Aizawa, "Initial dimensional change of composites in dry and wet conditions," Journal of Dental Research, vol. 62, no. 1, pp. 28-31, 1983.

[7] A. J. Feilzer, A. J. De Gee, and C. L. Davidson, "Relaxation of polymerization contraction shear stress by hygroscopic expansion," Journal of Dental Research, vol. 69, no. 1, pp. 3639, 1990.

[8] K. Asaoka and S. Hirano, "Diffusion coefficient of water through dental composite resin," Biomaterials, vol. 24, no. 6, pp. 975-979, 2003.

[9] P. L. Fan, R. M. Schumacher, K. Azzolin, R. Geary, and F. C. Eichmiller, "Curing-light intensity and depth of cure of resinbased composites tested according to international standards," Journal of the American Dental Association, vol. 133, no. 4, pp. 429-434, 2002.

[10] L. S. Türkün and M. Türkün, “The effect of one-step polishing system on the surface roughness of three esthetic resin composite materials," Operative Dentistry, vol. 29, no. 2, pp. 203-211, 2004.

[11] J. C. Setcos, B. Tarim, and S. Suzuki, "Surface finish produced on resin composites by new polishing systems," Quintessence International, vol. 30, no. 3, pp. 169-173, 1999.

[12] T. M. Chen and G. M. Brauer, "Solvent effects on bonding organo-silane to silica surfaces," Journal of Dental Research, vol. 61, no. 12, pp. 1439-1443, 1982.

[13] P. L. Fan, A. Edahl, R. L. Leung, and J. W. Stanford, "Alternative interpretations of water sorption values of composite resins," Journal of Dental Research, vol. 64, no. 1, pp. 78-80, 1985.

[14] C. Santos, R. L. Clarke, M. Braden, F. Guitian, and K. W. M. Davy, "Water absorption characteristics of dental composites incorporating hydroxyapatite filler," Biomaterials, vol. 23, no. 8, pp. 1897-1904, 2002.

[15] K. J. M. Söderholm, R. Mukherjee, and J. Longmate, "Filler leachability of composites stored in distilled water or artificial saliva," Journal of Dental Research, vol. 75, no. 9, pp. 16921699, 1996.

[16] K. J. M. Soderholm, "Leaking of fillers in dental composites," Journal of Dental Research, vol. 62, no. 2, pp. 126-130, 1983.

[17] J. G. Calais and K. J. M. Soderholm, "Influence of filler type and water exposure on flexural strength of experimental composite resins," Journal of Dental Research, vol. 67, no. 5, pp. 836-840, 1988.

[18] E. Mortier, D. A. Gerdolle, B. Jacquot, and M. M. Panighi, "Importance of water sorption and solubility studies for couple bonding agent_-resin-based filling material," Operative Dentistry, vol. 29, no. 6, pp. 669-676, 2004.

[19] M. N. Hegde and B. Biradar, "Evaluation of weight change of three different light cured composite restorative materials stored in water-an in-vitro study," Journal of Conservative Dentistry, vol. 13, pp. 109-114, 2008.

[20] L. A. Knobloch, R. E. Kerby, K. McMillen, and N. Clelland, "Solubility and sorption of resin-based luting cements," Operative Dentistry, vol. 25, no. 5, pp. 434-440, 2000.

[21] I. Sideridou, D. S. Achilias, C. Spyroudi, and M. Karabela, "Water sorption characteristics of light-cured dental resins and composites based on Bis-EMA/PCDMA," Biomaterials, vol. 25, no. 2, pp. 367-376, 2004.

[22] N. Martin, N. M. Jedynakiewicz, and A. C. Fisher, "Hygroscopic expansion and solubility of composite restoratives," Dental Materials, vol. 19, no. 2, pp. 77-86, 2003.

[23] H. Oysaed and I. E. Ruyter, "Water sorption and filler characteristics of composites for use in posterior teeth," Journal of Dental Research, vol. 65, no. 11, pp. 1315-1318, 1986.

[24] J. L. Ferracane, "Hygroscopic and hydrolytic effects in dental polymer networks," Dental Materials, vol. 22, no. 3, pp. 211222, 2006.

[25] Y. Iwami, H. Yamamoto, W. Sato, K. Kawai, M. Torii, and S. Ebisu, "Weight change of various light-cured restorative materials after water immersion," Operative Dentistry, vol. 23, no. 3, pp. 132-137, 1998. 


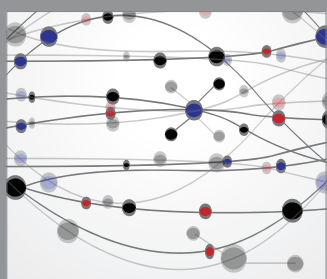

The Scientific World Journal
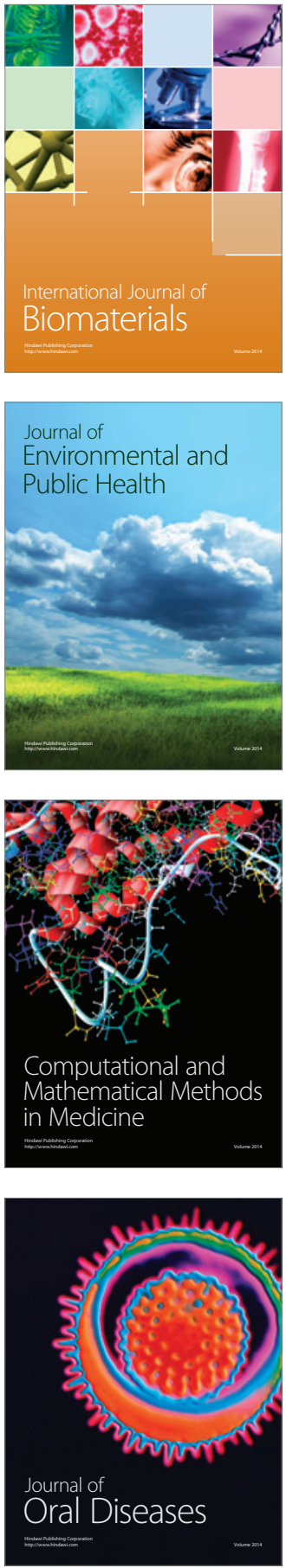
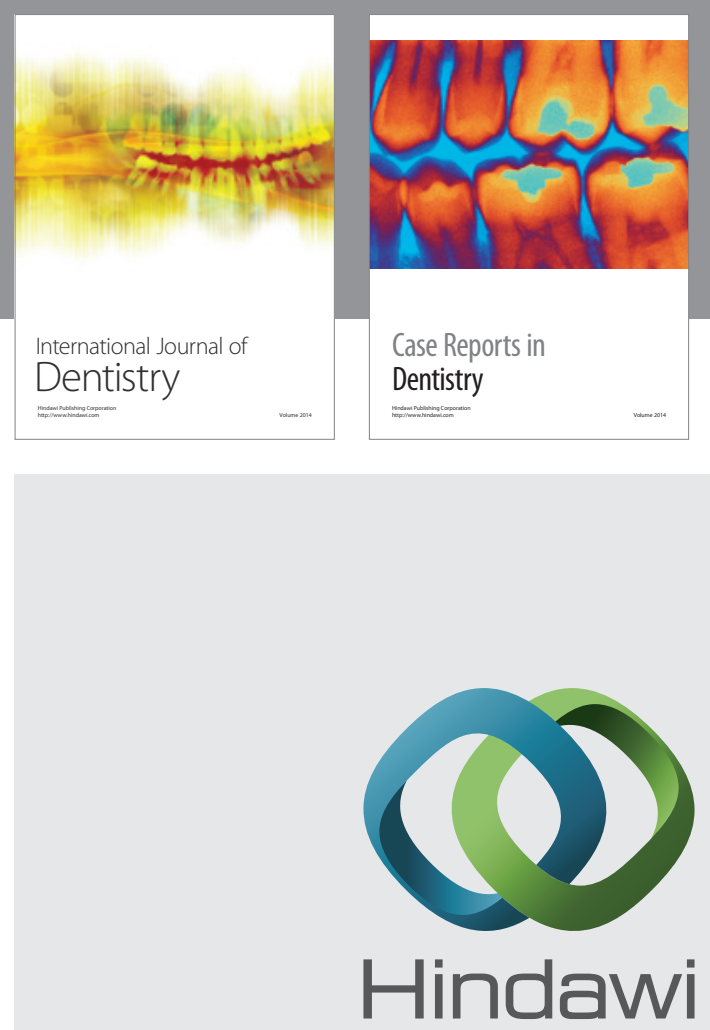

Submit your manuscripts at

http://www.hindawi.com
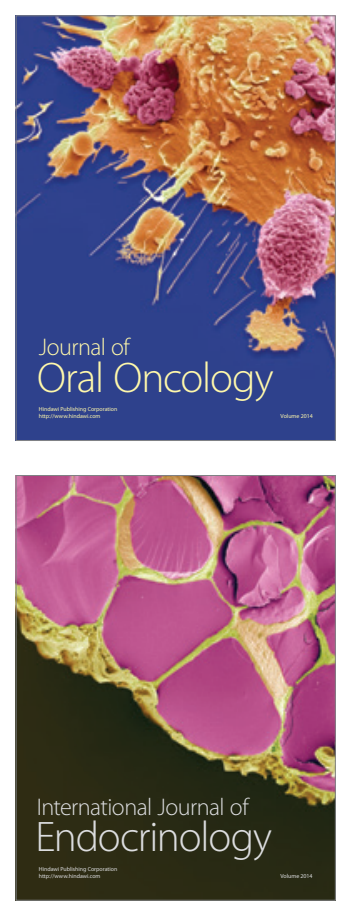
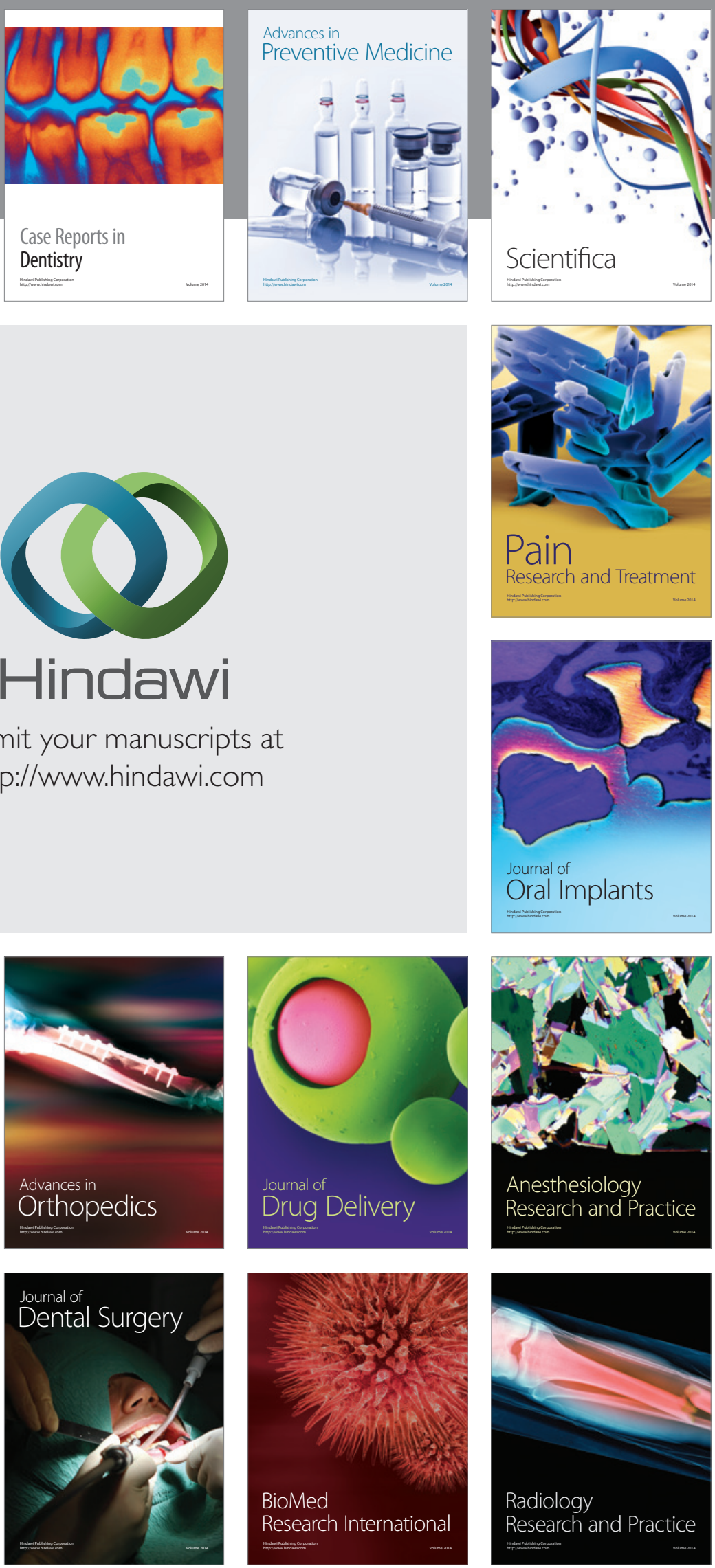